\title{
Central Body in the Male Reproductive Cells of the Silkworm with Special Reference to a Peculiarity of Centriole Division in Meiosis
}

\author{
Katumi Tanaka \\ National Institute of Genetics, Misima, Japan
}

Received March 28, 1955

\section{Introduction}

It is widely accepted that centrioles double during every mitotic divisiou, so that the constancy of their number is retained in all cells.

The behavior of centrioles in meiosis, also, has been investigated by various authors. According to von Lenhossék (1898), the first who has traced the centrosome throughout all stages of the spermatogenesis, spermatogonia and spermatocytes of the rat have two spherical centrioles, which are distributed between the two spindle poles of the first maturation division. Each of them splits into two globules during or after the cell division, the two new centrioles are distributed between the two poles in the second division and divide again, so that each spermatid receives a diplosome. That is to say, according to him the centrioles behave in meiosis in quite a similar manner as in two successive mitotic divisions.

Later, the centrosome has been observed in male and female reproductive cells of various animals, birds, reptiles, insects, etc. The observations were not in good agreement with those of von Lenhossék. Extensive reviews of Johnson (1932) and Risley (1936), however, pointed out no definite difference of centriole division between somatic and meiotic divisions. This may be the reason why in the illustrations of meiosis in almost all text-books, the centrioles are shown as dividing once during the first maturation division and then again during the second division.

Central bodies in reproductive cells have been described most extensively in insects (Meves, 1897; Cretschmar, 1928; Knaben, 1931, etc.) including the silkworm (Kawaguchi, 1934; Machida, 1935; Tsujita, 1947). However, more detailed research seemed to be desired in this field to reach definite conclusions. In his previous papers (1944 a, b), the present author has pointed out the peculiarity of centriole division in meiosis on the basis of his observations of male and female reproductive cells of the guinea-pig. The present work was attempted in order to establish any common characteristics in the behavior of centrioles from a comparative study of meiosis in insects and higher animals.

\section{Material and methods}

The "Chiyozuru" race, a Japanese bivoline race of the silkworm, Bombyx 
mori, was used. Larvae were obtained from the Department of Sericulture, Faculty of Agriculture, Kyushu University, to which the author wishes to express his indebtedness.

The testes were taken from the larvae on the first or the second day of the fifth instar. The material was fixed either in Zenker's fluid or Makino's fluid, both of which have proved from my experience to be most satisfactory for centrosome staining. The axial filaments and the idiozomes can be demonstrated better in Zenker preparations. Makino's fluid, a mixture of saturated aqueous picric acid solution 25, $10 \%$ formaldehyde 5, saturated sublimate solution 5 and glacial acetic acid 3 , came up to our expectation for analytical observation of centrioles, producing distinct and well defined configurations.

Osmic acid was not used, since osmic fixation is apt to stain the centrioles as somewhat larger bodies with less clear-cut boundary than in Zenker's and Makino's fixations and to cover fine details.

The material was embedded in paraffin, cut in serial sections 6-7 $\mu$ thick and stained either in Heidenhain's iron hematoxylin or in hematoxylin and eosin.

\section{Observations}

1) Spermatogonia (Pl. XIV, fig. 1). The spermatogonia, spherical cells of approximately $8 \mu$ in diameter, are located in cysts, which have yet no lumen. The nuclei are spherical, $4-5 \mu$ in size and situated eccentrically in the cells.

The centrosome is clearly observable in every gonium. In the resting stage it lies in the wider area of cytoplasm near the nucleus. It consists of an idiozome and centrioles. The idiozome, an ellipsoidal body of $1.5 \times 2 \mu$ in size, appeared to be homogeneous in our preparations, being in good contrast with other cytoplasmic portions of fine granular appearance. After Zenker's fixation, the idiozome stains lighter than the surrounding cytoplasm, where mitochondria are accumulated. On the contrary, in the preparations fixed with Makino's mixture, which dissolves all the mitochondrial elements, the idiozome appears rather darker than its surroundings.

At the center of the idiozome lies a pair of short rodshaped centrioles. Their longitudinal axes run most frequently parallel with each other. The two centrioles always lie close together. In extreme cases they are almost in contact, so that inadequate fixation and overstaining may cause one to mistake them for a single large globule, though it is not in the least difficult to avoid the mistake by careful fixation and staining.

2) Primary spermatocytes (figs. 2-11). During the early growth period of the primary spermatocytes the centrosome scarcely changes its shape throughout the different nuclear stages (fig. 2).

The cells begin to increase their size slowly (fig. 3, later zygotene stage) and reach a size of $10-12 \mu$ at the pachytene stage (fig. 4). The nuclei 


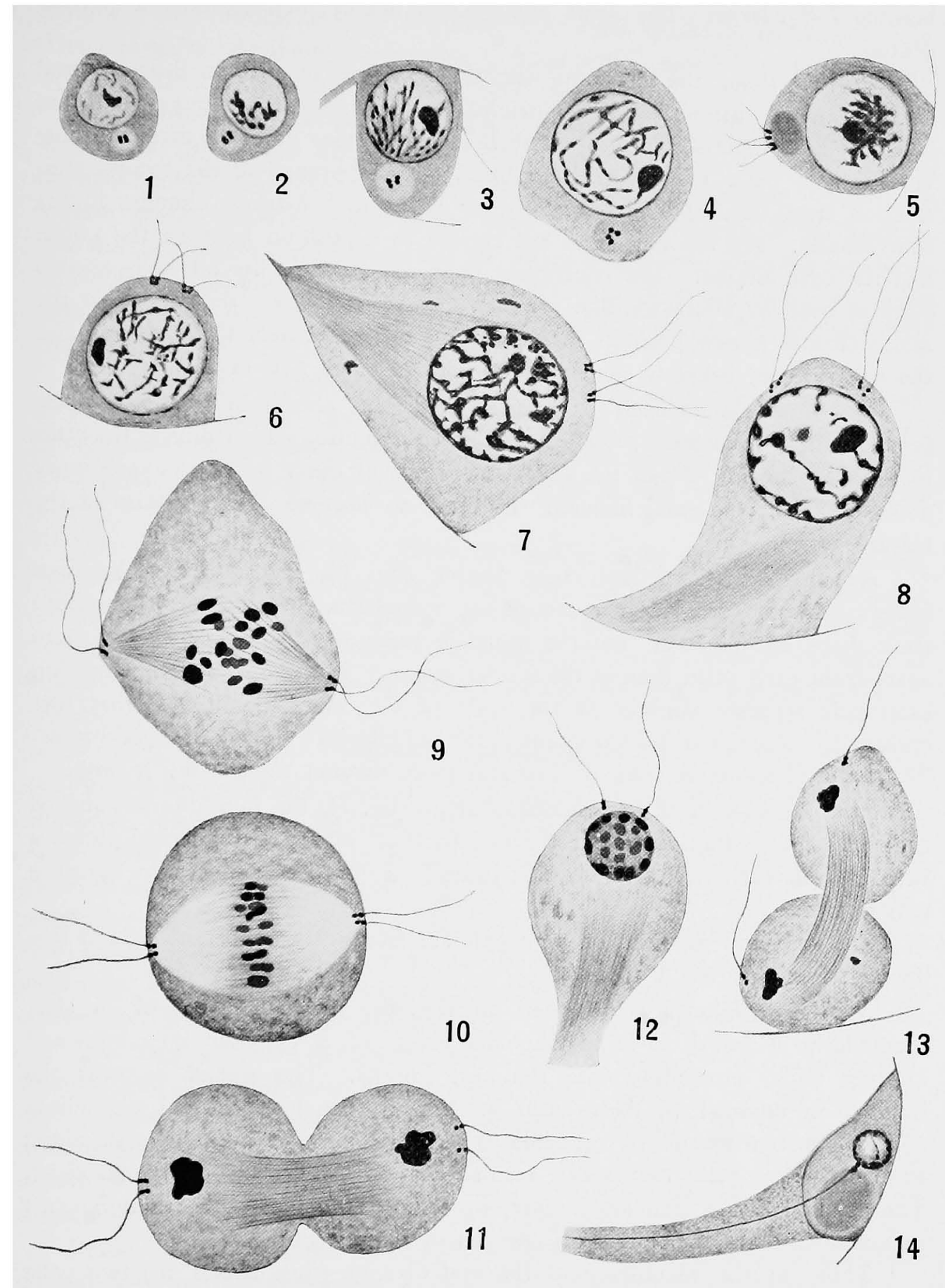

Tanaka: Central Body in the Male Reproductive Cells of the Silkworm 
become 7-8 $\mu$ large. The cysts enlarge as a whole forming lumina at their centers.

By this time, the idiozome slightly increases in size, to $2.5 \times 3 \mu$ and becomes more distinct. The centrioles become somewhat longer and are constricted at their midst into dumbell-shaped bodies or often divided transversely into pairs of spherical granules. The approach of the second contraction stage (fig. 5) is characterized by rapid and marked changes in the centrosomes. All the idiozomes are carried to a position between the nuclei and the cyst lumina. The centrioles, now recognizable in all cells as two pairs of oval or short rod-like granules, move out from the center of the idiozome into a new position in the narrow space between the idiozome and the cell surface, being in contact with both of these two organs.

Two centrioles of each pair lie close together, almost in contact at their proximal tips, frequently presenting a $\mathrm{V}$-shaped figure, which directs the arms to the cyst lumen. From the tip of each arm of the $\mathrm{V}$ issues an exceedingly delicate thread, the axial filament, destined to become the flagellum of the mature sperm.

As soon as the diffuse stage begins (fig. 6), the idiozome becomes indistinguishable from the surrounding cytoplasm. The centrioles retain their shape and position, but the centriole pairs seem to be somewhat more apart from each other than in the former stages. The two centrioles forming each pair separate slightly at the apex of V. They elongate further, occasionally become constricted again at the middle into dumbell-shaped bodies. The axial filaments become thicker and more distinct threads $6-7 \mu$ long.

At the approach of the diakinesis stage (fig. 7), the four dumbell-shaped centrioles divide transversely at the constrictions into eight spherical globules in each cell, each two globules constituting a pair, the four pairs forming two groups.

The proximal granules of each pair are frequently almost in contact two by two, retaining the $\mathrm{V}$-figures.

As the diakinesis stage goes on (fig. 8), the cell increases in size, particularly in length so as to take the shape of a cylinder $20 \mu$ long and $12-15 \mu$ wide, protruding into the cyst lumina. The nuclei lie near the lumina, in contrast to their basal position in usual cylindrical epithelium cells. The two groups of centriole pairs move apart from each other along the cell surface until they reach almost the opposite sides of the nucleus. The axial filaments elongate further, exceeding $30 \mu$ in length, though exact measurements are impossible on account of their strong winding.

Thus, at the metaphase of the first division (figs. 9 and 10) two pairs of spherical centrioles are found lying at each spindle pole.

The central apparatus remains unchanged until the end of anaphase. At the telophase (fig. 11), when the chromosomes assemble together into tassement polaire, the central body is in contact with the cell surface near the 
daughter chromosome group, extruding two axial filaments from each pole. The two pairs of spherical centrioles lie frequently somewhat apart from each other, so that a typical $\mathrm{V}$ is now seldom observable.

3) Secondary spermatocytes (figs. 12 and 13). In the reconstruction stage (fig. 12) of the first division, spherical nuclei are formed with well defined nuclear membrane containing 28 dyads, $3 \mu$ in diameter. The interkinesis passes quickly. The dyads move to the periphery of the nucleus. The nucleus enlarges and the nuclear membrane disappears, when the metaphase of the second division begins. By this time the centriole pairs, extruding axial filaments from the distal granules into the lumen, move apart $180^{\circ}$ from each other.

Thus, in the metaphase of the second division each pole exhibits a pair of spherical centrioles. At the telophase (fig. 13) the chromosomes form a group, tassement polaire, while the centrosome lies near the daughter chromosome group contacting the cell surface, without any visible change of its shape.

4) Spermatids (fig. 14). When the nucleus of the spermatid is reformed, the cell exhibits a pair of spherical centrioles, the proximal granule being in contact with the nuclear surface and the distal one serving as the basal corpuscle of the axial filament. Thereafter, the axial filament increases in length to a flagellum, while the cell is transformed into a mature sperm.

\section{Discussion and conclusion}

The behavior of the central body during the maturation divisions of the silkworm resembles in its principal features that observed by the present author $(1944 \mathrm{a})$ in the guinea-pig. However, some differences should be pointed out. In the guinea-pig, cells of a given stage exhibit a remarkable constancy in the composition of their central bodies, while in the silkworm the changes of the centrioles seem to be carried out not always quite concordantly with those of the nuclei, though a possibility remains that these discrepancy is not true, but resulted from slight technical inconsistencies.

The time, at which the axial filaments begin to project from the centrioles, may be quite variable according to the animal species. For instances, in the guinea-pig they appear at the reconstruction stage of the spermatid nucleus and, on the other hand, in the silkworm as early as in the growth period of the primary spermatocyte. One may classify the types of divisions according to this difference as Johnson (1932) and Risley (1936) have done.

Risley claimed that the presence of somewhat long centrioles is the only characteristic of the centrosome of reproductive cells. This hypothesis, however, proved to be not always true, as found in various animals, including the guinea-pig and the silkworm.

Though descriptions in the literature show a wide divergency, the majority of them seem to agree in principle on the following pattern of 
centrosome behavior: the number of the centrioles does not increase after the diakinesis stage. In other words, the total amount of centrioles remains unchanged throughout the two meiotic divisions, so that each secondary sperma-

A

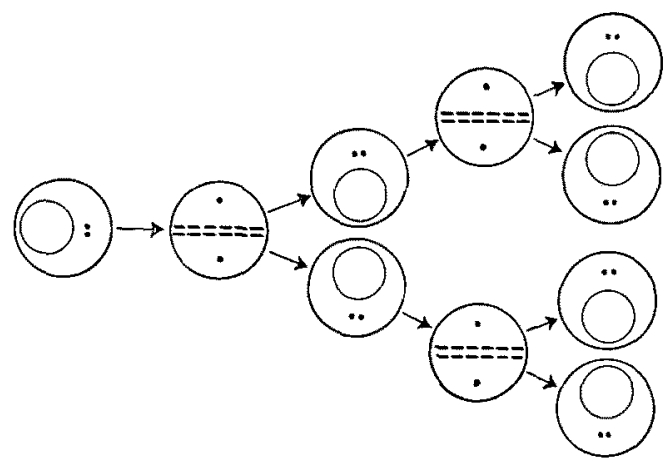

B

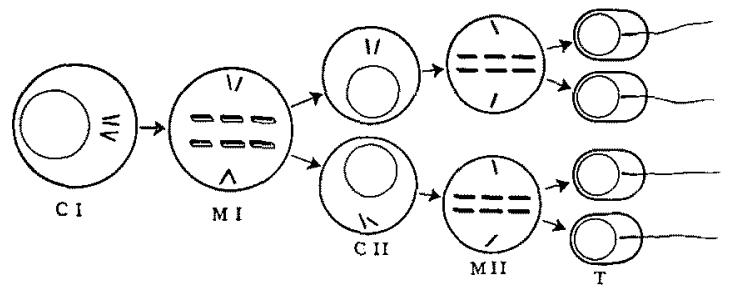

$\mathrm{C}$

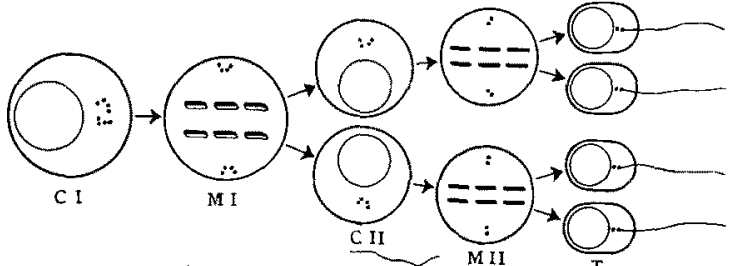

D

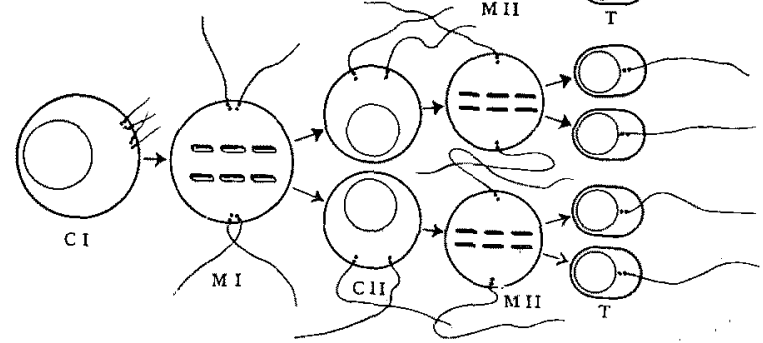

Text-fig. 1. Schemata of the centriole division in mitotic and meiotic divisions. A, two successive somatic mitosis; B, C and D, meiosis (B, Gryllidae, after Johnson and tortoise, after Risley; C, guinea-pig, after the author's observations; $D$, silkworm.).

$\mathrm{CI}$, diakinesis stage of primary spermatocytes; MI, metaphase of the first maturation division; CII secondary spermatocytes; MII, metaphase of the second division; $\mathrm{T}$, spermatids. tocyte receives a half and each spermatid only one fourth of the centrioles contained in a primary spermatocyte. This relation is illustrated schematically in text-figures $1 \mathrm{~B}-\mathrm{D}$. In the somatic division (text-fig. 1 A) the daughter cells have the same number of centrioles as the mother cells, so that the total amount of centrioles doubles during every cell division, being in marked contrast to the meiotic divisions.

Thus, the centrioles are in the same numerical relations as the chromosomes. As text-figures $1 \mathrm{~B}, \mathrm{C}$ and D show, four pairs of spherical centrioles or four long rod-shaped ones are present at the time of tetrad formation in the diakinesis stage, two pairs or two centrioles are contained in the cell when the dyads are distributed at interkinesis and a pair of spherical ones or a single rod-like one is included in the spermatid, in which only monads are present.

According to Ris (1947), in somatic mitosis the quantity of desoxyribonucleic acid increases during the prophase to reach at metaphase twice the amount contained in the mother cell, half of which is given to each daughter cell, while, in meiosis, the substance doubles in quantity during the prophase 
but not increase after the metaphase of the first division. This conformity should be regarded as significant from the point of view of the mechanism of centriole divisions and possibly of the meiotic divisions as a whole.

\section{Summary}

1) The central body of the silkworm was traced in unbroken continuity from resting spermatogonia to spermatids, and the observations were compared with those in other animals.

2) Each spermatogonium exhibits a centrosome, which consists of an idiozome and a pair of short rod-shaped centrioles at the midst of the idiozome.

3) At the beginning of the growth period of the primary spermatocyte, each centriole divides into a pair of globules, so that two pairs of spherical granules are produced in each cell. At the second contraction stage, the centrioles move out of the idiozome into the area between the cell surface and the idiozome. The four centrioles elongate into elliptical or rod-shaped bodies, each extruding an axial filament from the distal tip and they are frequently in contact two by two at the proximal tips, forming two V's. The idiozome disappears in the dispersion stage.

By the diakinesis stage, the centrioles divide again into four pairs of spherical granules. Thus, two pairs of spherical centrioles are distributed to each pole of the first maturation division.

4) During the telophase and interkinesis, the two pairs of centrioles separate and move until they reach the positions $180^{\circ}$ apart, so that a diplosome is found at each pole of the second maturation division which is distributed unchanged to each spermatid.

5) It is most significant that the centrioles increase in number up to the diakinesis stage to become as many as in all four spermatids together, and so the total amount of centrioles remains unchanged throughout the two meiotic divisions, in marked contrast with the somatic divisions. This relation is in agreement with the majority of extensive observations carried out by many authors on various animal species.

\section{References}

Baumgartner. W. J. 1929. Die Spermatogenese bei einer Grille (Nemobius fasciatus). Z. Zellforsch. 9.

- 1931. The centriole in the domestic duck. Anat. Rec. 48.

Buder, J. E. 1917. Die Spermatogenese von Deilephila euphorbiae L. Arch. Zellforsch. 14.

Charlton, H. H. 1921. The spermatogenesis of Lepisma domestica. J. Morph. 35.

Chudoba, S. 1930. Appareil centriolaire dans les cellules sexuelles males chez Dytiseus marginalis L. C. R. B. 105.

Cretschmar, M. 1928. Das Verhalten der Chromosome bei der Spermatogenese von Orgyia thyellina und antiqua sowie eines ihrer Bastarde. Z. Zellforsch. 7.

Johnson, H. H. 1932. Centrioles and other cytoplasmic components of the male germ cells of the gryllidae. Z. wiss. Zool. 140. 
Kawaguchi, E. 1934. Zytologische Untersuchungen am Seidenspinner und seiner Verwandten. II. Japanese J. Genetics 10.

Knaben, N. 1931. Spermatogenese bei Tischeria angusticollella. Z. Zellforsch. 13.

Korff, K, von. 1901. Weitere Beobachtungen über das Vorkommen V-förmigen Centralkörper. Anat. Anz. 19.

Lenhossék, M. von. 1898. Untersuchungen über Spermatogenese. Arch. mikr. Anat. 51.

Machida, J. 1935. The spermatogenesis of the silkworm, Bombyx mori L. Dobutsugaku Zasshi 47.

Meves, F. 1897. Ueber Centralkörper in männlichen Geschlechtszellen von Schmetterlingen. Anat. Anz. 14.

Minouchi, O. 1936. Cytologische Stadien über das Ei von Polystomum integerrimum von der Eiablage bis zu den frühen Furchungsstadien. Z. Zellforsch. 24.

Payne, F. 1927. Some cytoplasmic structures in the male germ cells of Gelastocoris oculatus (toad-bug). J. Morph. 43.

Ris, H. 1947. The composition of chromosomes during mitosis and meiosis. Cold Spring Harbor Symposia on Quantitative Biology XII.

Risley, P. L. 1936. Centrioles in germ cells of turtles, including observations on the manchette in spermiogenesis. Z. mikr. Zool. 148.

Tanaka, K. 1944a. Das Zytozentrum in den Hodenzellen des Meerschweinchens. II. Hukuoka Acta Medica 37.

- 1944b. Das Zytozentrum in einigen Zellen des Meerschweinchenovariums. ibid.

Tsujita, M. 1947. Spermatogenesis of Hemerophila atrilineata Butler. Bull. Sericult. Exp. Station (Tokyo). 12.

Wassilieff, A. von. 1904. Zur Spermatogenese bei Blatta germanica. Anat. Anz. 25.

\section{Explanation of Plate XIV}

Figs. 1-14. Camera lucida drawings, $\times 1600,1-4,9$ and 14 are drawn after Zenker's and others after Makino's fixation. 1, spermatogonia. 2, early growth period of primary spermatocytes. 3, later zygotene stage. 4, pachytene stage. 5, second contraction stage. 6 , early diffuse stage. 7 , diakinesis stage. 8 , later diakinesis stage. 9 and 10, metaphase of the first maturation division. 11, telophase. 12 and 13, secondary spermatocytes. 14, spermatid. 